\title{
Synthesis, structure and solid-state electrical conductivity of bis(1,2-diphenylethylene-1,2-dithiolate)nickel(II)
}

\author{
ARGHYA DUTTA $^{\mathrm{a}}$, ARNAB CHATTERJEE $^{\mathrm{a}}$, KISHALAY BHAR $^{\mathrm{b}}$, ANINDITA BANERJEE $^{\mathrm{c}}$ \\ and RAJARSHI GHOSH ${ }^{\mathrm{a}, *}$ \\ ${ }^{a}$ Department of Chemistry, The University of Burdwan, Burdwan 713 104, West Bengal, India \\ b Department of Chemistry, School of Chemical Science and Pharmacy, Bandar Sindri 305817 , \\ Rajasthan, India \\ ${ }^{\mathrm{c}}$ Department of Physics, The University of Burdwan, Burdwan 713 104, West Bengal, India \\ E-mail:rghosh@chem.buruniv.ac.in
}

MS received 8 April 2019; revised 5 July 2019; accepted 23 July 2019

\begin{abstract}
One nickel(II)-dithiolene complex bis(1,2-diphenylethylene-1,2-dithiolate)nickel(II) has been synthesized and crystallographically characterized. The complex is square planar at its metal centre. The compound in its solid-state is found to conduct electricity at room temperature. Variation of conduction is also found on raising the temperature. Instead of a metal...metal orbital overlap, the electron density is expected here to pass through some other covalent and electrostatic bonds of the compound in solid-state resulting in electricity conduction.
\end{abstract}

Keywords. Ni(II) dithiolene complex; synthesis; X-ray structure; electricity conduction.

\section{Introduction}

Interest on metal dithiolene complexes has its root in the last few decades of the last century. ${ }^{1-3}$ Early literature on this type of metal complexes are concerned particularly on the synthesis, structure and reactivity. ${ }^{1-3}$ Later on, these were found to have its application in biology $y^{4,5}$ and more importantly in material science. ${ }^{6-10}$ In the latter area dithiolene complexes were found to be conducting, ${ }^{6,7}$ catalytic, ${ }^{8}$ non-linear optical, ${ }^{9}$ near IR absorbing, ${ }^{10}$ etc. The high electrical conductivity by pure metals is due to its enough overlap of atomic orbitals to produce the conduction path. In the case of molecular materials, the overlap of molecular orbitals is not sufficient enough for good electrical conductivity. Columnar stacking of molecules with larger atoms like chalcogens which makes the assembly well-packed by making interaction with next molecules in solid-state is found to be good. ${ }^{11}$ Here the conductivity depends on the bandgap between the HOMO-based valence band and LUMO-based conduction band. $\mathrm{Ni}$ (II)-dithiolene complexes being square planar in geometry and having sulpher as coordinating atoms in the ligand backbone are good candidates to conduct electricity. ${ }^{6}$ In this present report, with a little modification, we have synthesized a previously reported nickel(II)-dithiolene complex bis(1,2-diphenylethylene-1,2-dithiolate)nickel(II)(1) by Ma et al., ${ }^{12}$ and characterized it X-ray crystallographically. The compound was previously shown ${ }^{12}$ to be near IR absorbing. In our endeavour, we have found that the complex also conducts electricity semiconducting in its solid-state.

\section{Experimental}

\subsection{Preparation of the complex 1}

2.1a Chemicals, solvents and starting materials: High purity Benzoin (extra pure, 99\%; SRL, India), phosphorus pentasulfide (99\%; Sigma Aldrich, India), 1,4-dioxane (extra pure AR, 99.5\%; SRL, India) and all other solvents were purchased from the respective companies and used as received. Solvents were dried according to standard procedure and distilled prior to use.

*For correspondence

Electronic supplementary material: The online version of this article (https://doi.org/10.1007/s12039-019-1655-0) contains supplementary material, which is available to authorized users. 


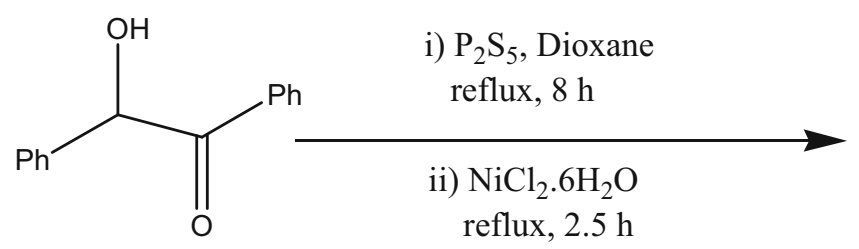

Benzoin

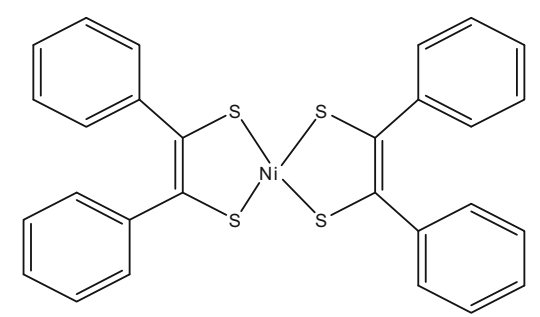

1

Scheme 1. The synthesis of bis(1,2-diphenylethylene-1,2-dithiolate)nickel(II) (1).

2.1b Synthesis of 1: 1 was synthesized (Scheme 1) using a reported method ${ }^{12}$ with a little modification. Benzoin $(4.24 \mathrm{~g}$, $20 \mathrm{mmol})$ was refluxed with $\mathrm{P}_{2} \mathrm{~S}_{5}(8 \mathrm{~g}, 36 \mathrm{mmol})$ in $50 \mathrm{~mL}$ of dry dioxane for $8 \mathrm{~h}$. During this period, the thiophosphoric ester of dithiobenzoin was formed. After $8 \mathrm{~h}$ of reflux, the hot reaction mixture was filtered to remove excess $\mathrm{P}_{2} \mathrm{~S}_{5}$ and a solution of $\mathrm{NiCl}_{2} \cdot 6 \mathrm{H}_{2} \mathrm{O}(1.16 \mathrm{~g}, 4.9 \mathrm{mmol})$ in $8 \mathrm{~mL}$ of distilled water was added to it and refluxed for $2.5 \mathrm{~h}$ and cooled by ice-water bath for $18 \mathrm{~h}$. A deep greenish crude complex was formed and collected by filtration, washed with a little amount of water, ether, alcohol and dioxane. It was then dried to give the crude complex. Purification was conducted by recrystallization from dichloromethane to afford greenishblack crystals. Yield: $1.30 \mathrm{~g}(12 \%)$. IR $\left(\mathrm{KBr}, \mathrm{cm}^{-1}\right)$ : 1357 , 1136, 1026, 880, 746, 696; UV-Vis (nm): 269, 314, 593.

\subsection{Physical measurements}

IR ( $\mathrm{KBr}$ discs, $4000-500 \mathrm{~cm}^{-1}$ ) and UV-Vis spectra were recorded on Shimadzu IR Prestige spectrometer and Shimadzu UV-Vis 2450 spectrophotometer, respectively. Electrical conductivity was measured in the Keithley 2400 source meter. The molecular orbital calculation was done using the GAUSSIAN 05 software package.

\section{$2.3 X$-ray diffraction}

Single crystal X-ray crystallographic analysis of $\mathbf{1}$ was carried out on a Bruker SMART APEX II CCD diffractometer using Mo-K $\alpha$ radiation $(\lambda=0.71073 \AA)$, Diffraction data were collected at $296 \mathrm{~K}$ and was identified as P $2_{1} / \mathrm{n}$ space group. Crystal data and refinement details are listed in Table 1. The structure was solved by direct methods, and the structure solution and refinement were based on $|F|^{2}$.

\section{Results and Discussion}

\subsection{Synthesis and formulation}

1 was synthesized (Scheme 1) using a reported method $^{12}$ with a little modification. The reaction mixture of benzoin and phosphorus pentasulphide after refluxing for eight hours was filtered to remove excess phosphorus pentasulphide. To this mixture aqueous solution of nickel(II) chloride hexahydrate was gradually added and this final mixture was further refluxed for some hours. In our method, the reaction time was to some extent reduced in comparison to reported literature. ${ }^{12}$ After this, the mixture was ice-cooled and green coloured crystals were formed from this. This was recrystallized from dichloromethane to get good quality X-ray grade single crystals.

\section{$3.2 \quad X$-ray structure}

Single crystal X-ray diffraction data (Table 1) were obtained for 1 to get its molecular structure (Figure 1). From bond angle bond distance data (Table 2) it can be found that $\mathrm{Ni}(\mathrm{II})$ is in square planar geometry. The four $\mathrm{S}-\mathrm{Ni}-\mathrm{S}$ bond angles are around $90^{\circ}$ and the Ni-S bonds are of equal value $(2.1187 \AA)$.

The square planar molecules of $\mathbf{1}$ are stacked to each other via strong intermolecular $\mathrm{C}-\mathrm{H} \cdots \pi$ interactions [C3-H3 $\cdots \mathrm{Cg}(4): 2.84 \AA, \mathrm{C} 3 \cdots \mathrm{Cg}(4): 3.650(6) \AA$, $\mathrm{C} 3-\mathrm{H} 3 \cdots \mathrm{Cg}(4)$ : $147^{\circ}$, symmetry code: $1+\mathrm{x}, \mathrm{y}, \mathrm{z}$; $\mathrm{Cg}(4)$ : C9-C10-C11-C12-C13-C14] and weak C-H $\cdots \mathrm{S}$ hydrogen bonds $[\mathrm{C} 14-\mathrm{H} 14 \cdots \mathrm{S} 1: 3.185 \AA$, C14-

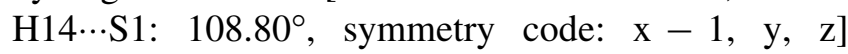
forming 1D layer along crystallographic $a$-axis (Figure 2). The Ni...Ni separation is equal to the length of the $a$-axis $5.9428(4) \AA$. Each 1D layer is further stabilised through intramolecular $\mathrm{C}-\mathrm{H} \cdots \pi$ interactions $[\mathrm{C} 10-\mathrm{H} 10 \cdots \mathrm{Cg}(3): 2.92 \AA, \mathrm{C} 10 \cdots \mathrm{Cg}(3): 3.557(6) \AA$,

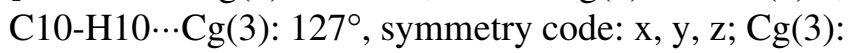
C2-C3-C4-C5-C6-C7] and weak C-H ‥S hydrogen

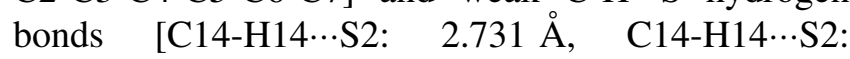
$102.37^{\circ}$ ] (Figure 2). These 1D layers are oriented in ABAB...fashion throughout the whole crystal lattice (Figure 3). The AA.../BB... layers are connected to each other through intermolecular $\pi-\pi$ stacking $\left[\mathrm{Cg}(4)-\mathrm{Cg}(4)\right.$ distance: $3.856(3) \AA$, dihedral angle: $0^{\circ}$, 
Table 1. Crystal data and structure refinement parameters for $\mathbf{1}$.

\begin{tabular}{ll}
\hline Parameters & \multicolumn{1}{c}{$\mathbf{1}$} \\
\hline Empirical formula & $\mathrm{C}_{28} \mathrm{H}_{20} \mathrm{~S}_{4} \mathrm{Ni}$ \\
Formula weight & 543.39 \\
Temperature (K) & $296(2)$ \\
Wavelength $(\AA)$ & 0.71073 \\
Crystal system & Monoclinic \\
Space group & $\mathrm{P} 2{ }_{1} / \mathrm{n}$ \\
a $(\AA)$ & $5.9428(4)$ \\
$\mathrm{b}(\AA)$ & $11.0892(8)$ \\
$\mathrm{c}(\AA)$ & $18.5997(14)$ \\
$\mathrm{V}\left(\AA^{3}\right)$ & $1224.63(15)$ \\
$\mathrm{Z}$ & 2 \\
$D_{\text {calc }}[\mathrm{g} / \mathrm{cc}]$ & 1.474 \\
$\mathrm{~F}(000)$ & 560.0 \\
$\theta$ range for data collection $\left({ }^{\circ}\right)$ & 3.558 to 24.985 \\
Reflections collected & 16932 \\
$\mathrm{~h} / \mathrm{k} / 1$ & $-7 / 7,-13 / 13,-22 / 22$ \\
Independent reflections $[\mathrm{R}($ int $)=0.0745]$ & 2130 \\
Completeness to $\theta$ & $99.7 \%$ \\
Goodness-of-fit on $\mathrm{F}^{2}$ & 1.177 \\
Final R indices $[\mathrm{I}>2$ sigma(I)] & $R_{1}=0.0493, w R_{2}=0.1528 ;$ \\
$\mathrm{R}$ indices (all data) & $R_{1}=0.0643, w R_{2}=0.1617 ;$ \\
Largest diff. peak and hole $\left(\mathrm{e} \AA^{-3}\right)$ & 1.006 and -0.665 \\
\hline
\end{tabular}

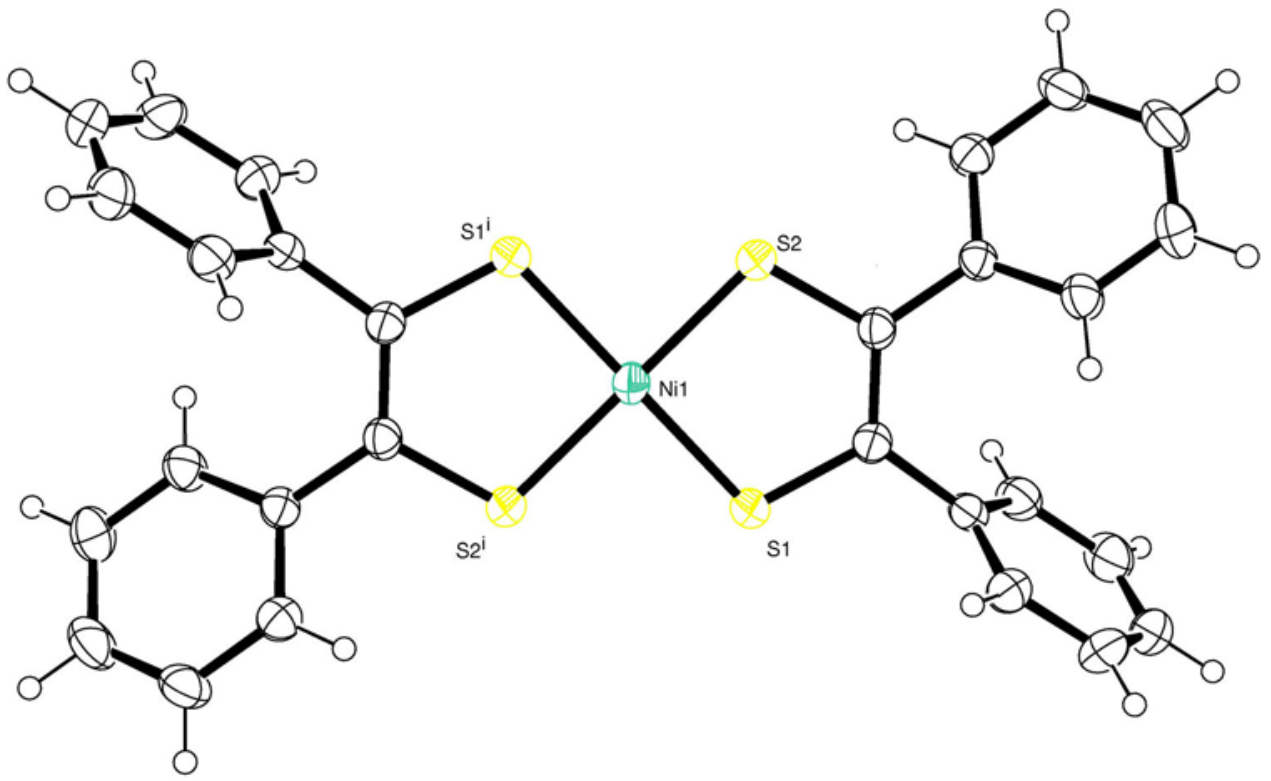

Figure 1. ORTEP of 1 with $40 \%$ ellipsoid probability.

slippage: $0.967 \AA$, symmetry code: $-1-\mathrm{x}, 1-\mathrm{y}$, $1-\mathrm{z}$ ] while $\mathrm{AB} \ldots$ layers are involved in intermolecular $\mathrm{C}-\mathrm{H} \cdots \pi$ interactions $[\mathrm{C} 11-\mathrm{H} 11 \cdots \mathrm{Cg}(3)$ : $2.79 \AA, \quad \mathrm{C} 11 \cdots \mathrm{Cg}(3): \quad 3.717(5) \AA, \quad \mathrm{C} 11-\mathrm{H} 11 \cdots \mathrm{Cg}(3)$ : $172^{\circ}$, symmetry code: $\left.-1 / 2-\mathrm{x}, 1 / 2+\mathrm{y}, 1 / 2-\mathrm{z}\right]$ as shown in Figure 4.

\subsection{Electrical conductivity of 1 and $M O$ calculation}

On the application of electrical potential 1 (with sample pellet thickness $0.08 \mathrm{~cm}$ and diameter $1.3 \mathrm{~cm}$ ) was found to conduct electricity $\left(9.47 \times 10^{-6} \mathrm{Scm}^{-1}\right.$ 
Table 2. Bond angle-bond distance parameter for $\mathbf{1}$.

\begin{tabular}{llll}
\hline Bond angles & & \multicolumn{2}{c}{ Bond distances } \\
\hline $\mathrm{S}(1)-\mathrm{Ni}(1)-\mathrm{S}(2)$ & $91.04(4)^{\circ}$ & $\mathrm{Ni}(1)-\mathrm{S}(1)$ & $2.1187(11) \AA$ \\
$\mathrm{S}(2)-\mathrm{Ni}(1)-\mathrm{S}(2)$ & $180.0^{\circ}$ & $\mathrm{Ni}(1)-\mathrm{S}(2)$ & $2.1187(11) \AA$ \\
\hline
\end{tabular}

at $288 \mathrm{~K}$ ) in solid-state. The electrical current-voltage plot (Figure 5) reveals that the current was of Ohmic type. Interestingly, on varying temperature and keeping the voltage in between -5 to $+5 \mathrm{~V}$ (by using Keithley 2400 source meter) the molecules behave like semiconducting materials (Figure 6). The conductivity

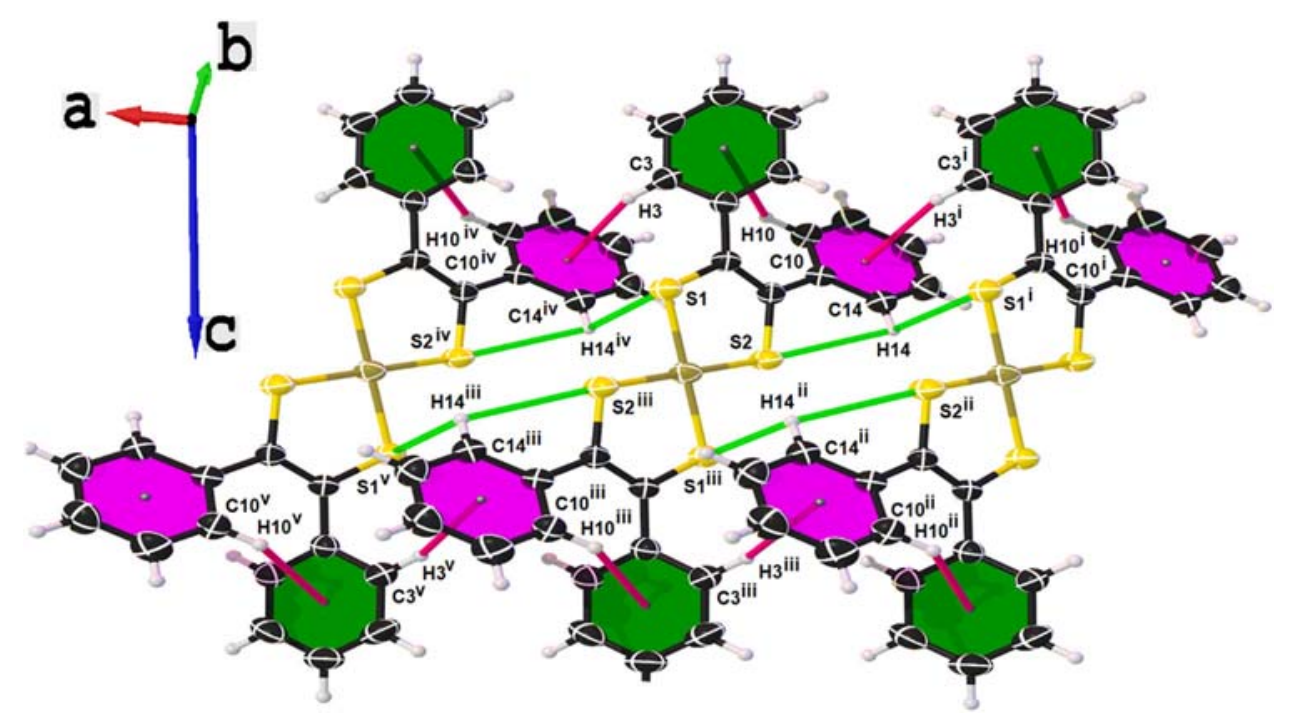

Figure 2. A view of 1D layer structure (A or B) along crystallographic $a$-axis involving intra- and intermolecular $\mathrm{C}-\mathrm{H} \cdots \pi$

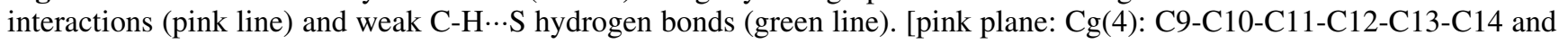
green plane: $\mathrm{Cg}(3)$ : $\mathrm{C} 2-\mathrm{C} 3-\mathrm{C} 4-\mathrm{C} 5-\mathrm{C} 6-\mathrm{C} 7]$.

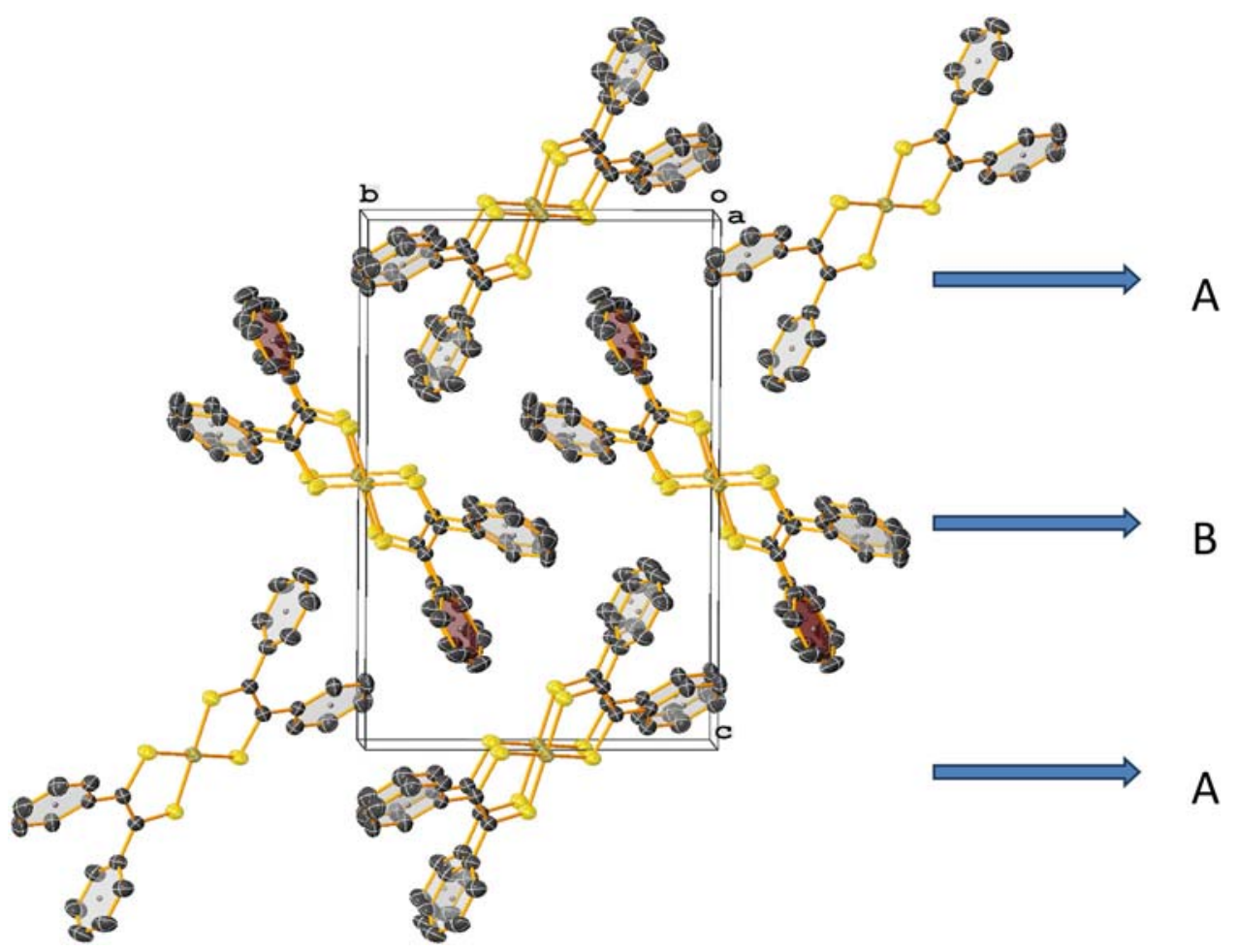

Figure 3. $\mathrm{A}$ view of $\mathrm{ABAB} \ldots$ the orientation of $1 \mathrm{D}$ layer structures in the crystal lattice. 


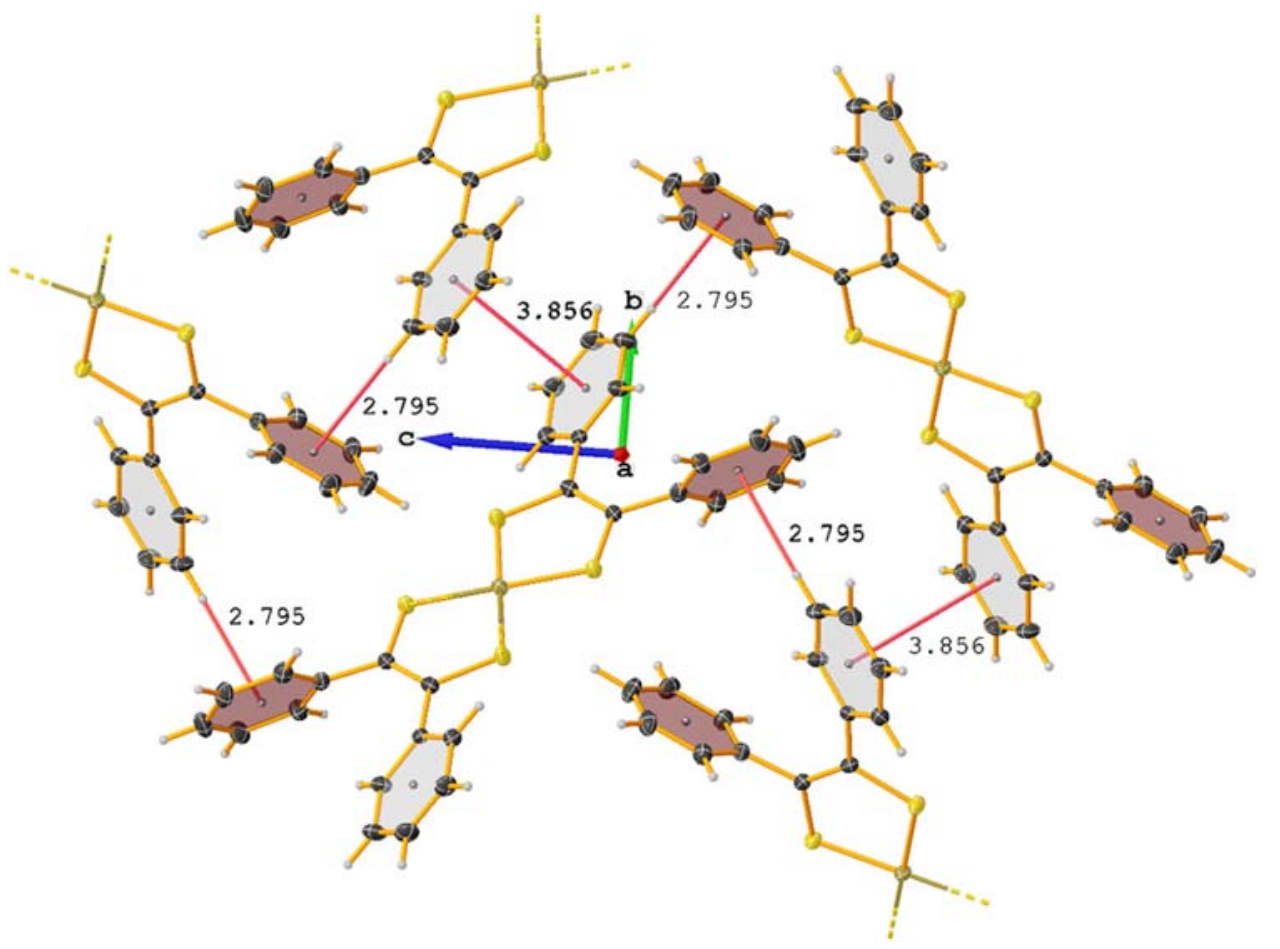

Figure 4. Intermolecular $\pi-\pi$ stacking and $\mathrm{C}-\mathrm{H} \cdots \pi$ interactions connecting $\mathrm{A}$ and $\mathrm{B}$ layers.

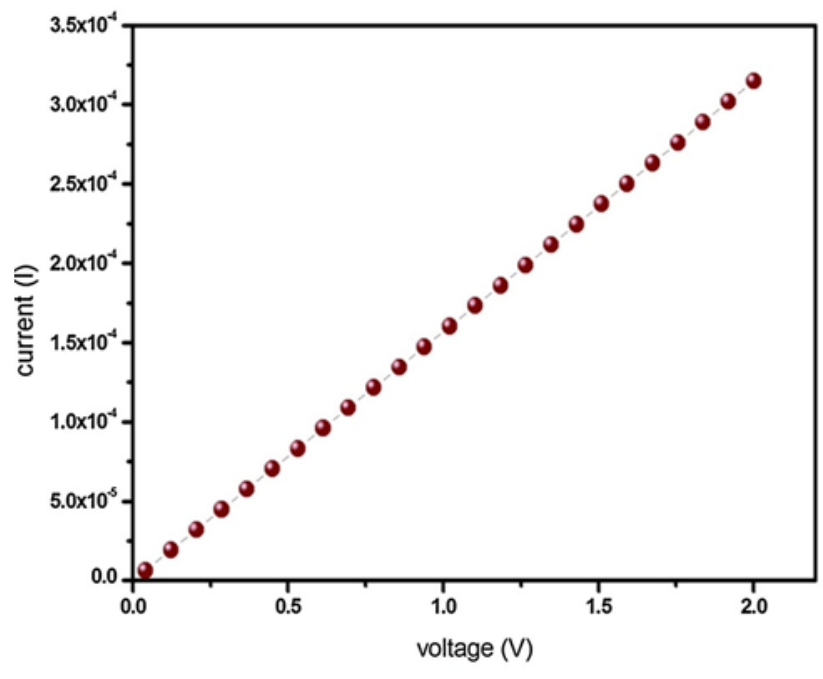

Figure 5. Electrical current vs voltage plot of $\mathbf{1}$.

varies from $1.96 \times 10^{-5} \mathrm{~S} \mathrm{~cm}^{-1} \quad(298 \mathrm{~K})$ to $1.12 \times 10^{-4} \mathrm{~S} \mathrm{~cm}^{-1}(470 \mathrm{~K})$.

Molecular Orbital calculation (using the B3LYP level and 6-31G basis set of GAUSSIAN 05 software package) shows that the nickel centre is rich in electron density (Figure 7(i)) and it may be assumed that this centre is responsible for electron passage to show the electrical conductivity. The LUMO of the molecule is found to be ligand centric (Figure 7(ii)).

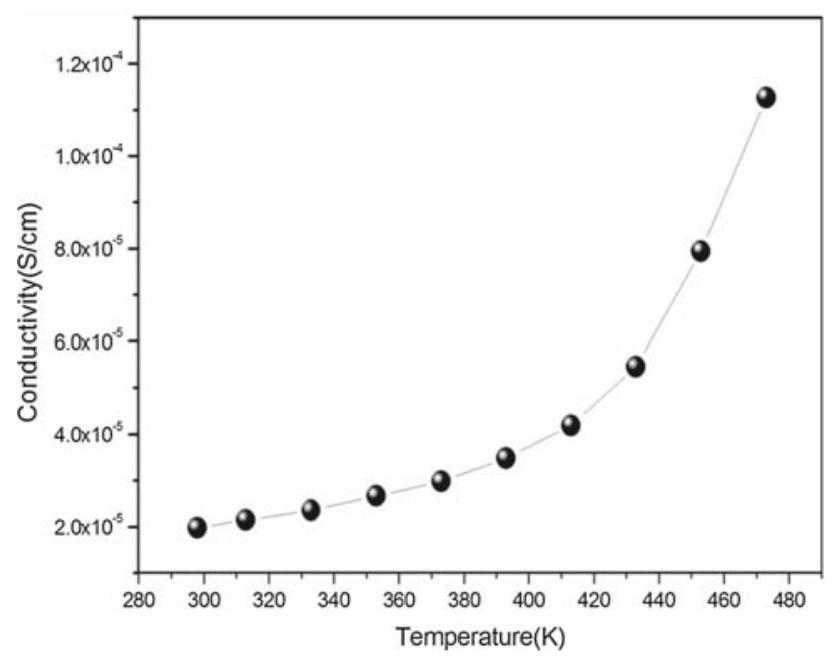

Figure 6. Conductivity at -5 to $+5 \mathrm{~V}$ with varying temperature.

In most of the square planar well-stacked platinum complexes, the reason for electrical conductivity is well understood. ${ }^{13}$ The close proximity of Pt...Pt centres in their complexes is suggestive of sufficient overlap between $\mathrm{dz}^{2}$ orbitals which forms the path to conduct electrons resulting electrical current. ${ }^{13}$ Few square planar $\mathrm{Ni}(\mathrm{II})$-dithiolene complexes ( $\mathrm{Ni}$ being the element in the same group of the periodic table (Group 10) with Pt) are there in literature which are found to conduct electricity. ${ }^{6}$ But to the best of our 


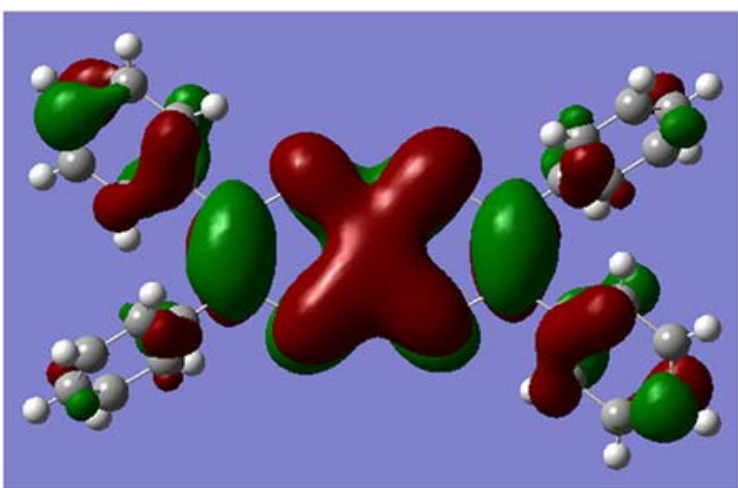

(i)

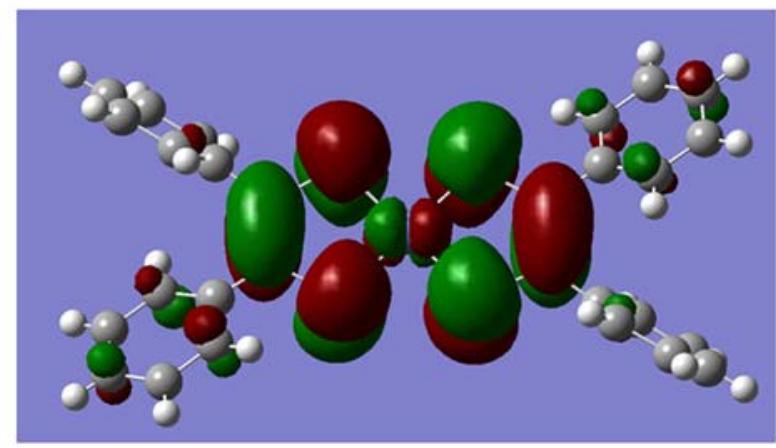

(ii)

Figure 7. (i) HOMO (metal centric) and (ii) LUMO (ligand centric) diagram.

effort, no report was found explaining the mechanism of this electrical conduction. In our case, the sufficiently long $\mathrm{Ni}$...Ni distance $(5.9428(4) \AA)$ is not favorable to suppose any orbital overlap between the metal centres. Despite, the reason for electrical conduction may be thought of as the passage of electron density from one $\mathrm{Ni}$ (II) centre to next $\mathrm{Ni}$ (II) centre through the ligand covalent and electrostatic bonds (through Ni1 to $\mathrm{S} 2$ to $\mathrm{H} 14$ to $\mathrm{S} 1^{\mathrm{i}}$ to next Ni centre, Figure 2). Travelling of electron density through several atoms (hence facing higher resistance) may be the reason for lower conductivity value of $\mathbf{1}$ in comparison to some other reports. ${ }^{6}$

\section{Conclusions}

In conclusion, it may be stated that the $\mathrm{Ni}(\mathrm{II})$-dithiolene complex (1) was synthesized using little modification of the previously reported method ${ }^{12}$ and X-ray crystallographically characterized. The compound, as like other Ni(II)-dithiolene compounds, ${ }^{6}$ are conducting electricity at room temperature in solid-state. On raising the temperature, the compound is found to behave like a semiconductor. The mechanism of this electrical conduction is tried to be understood from the molecular orbital calculations and solid-state packing diagrams. Considering all these, 1 may be a good addition to the coordination molecules which shows electrical conductivity in solid-state.

\section{Supplementary Information (SI)}

Supplementary figures S1-S2 are available at www.ias.ac. in/chemsci.

\section{Acknowledgements}

$\mathrm{AD}$ and $\mathrm{AC}$ are thankful to CSIR, India and DST-PURSE, India, respectively for their fellowships. We gratefully acknowledge USIC (Burdwan University) for SCXRD facility. Generous help by Dr. Abhigyan Dutta, Department of Physics, The University of Burdwan, by rendering solidstate electrical conductivity data is also gratefully acknowledged.

\section{References}

1. (a) Schrauzer G N, Mayweg V P and Heinrich W 1965 Concerning the synthesis of Dithio- $\alpha$-diketone complexes of Transition Metals from Thiophosphates of 1,2-Dithiols Inorg. Chem. 4 1615; (b) Schrauzer G N and Mayweg V P 1965 Preparation, Reactions, and Structure of Bisdithio- $\alpha$-diketone Complexes of Nickel, Palladium, and Platinum J. Am. Chem. Soc. 871483

2. (a) King R B and Eggers C A 1968 Organosulfur Derivatives of the Metal Carbonyls. X. Some Transition Metal Derivatives Containing Both $\pi$-Cyclopentadienyl and cis-1,2-Ethylenedithiolate Ligands Inorg. Chem. 7 340; (b) Schroth W 1965 Cis-und transdimercaptoäthylen Tetrahedron Lett. 6195

3. (a) Hoyer E, Dietzsch W, Henning H and Schroth W 1969 cis-Dimercaptoäthylenals Stammligand der Dithiolat-Chelate Chem. Ber. 102 603; (b) Wharton E J and McCleverty J A 1969 Transition-metal Dithiolenes. Part VIII. Metal Complexes of Tris-tetra-chlorobenzene-1,2-dithiol and related Compounds J. Chem. Soc. (A)2258; (c) Andersen J R, Patel V V and Engler E M 1978 Bis-1,2-dithiole chemistry: synthesis of compounds containing the $4,4^{\prime}$ bis-(1,3-dithiole) unit $T e$ trahedron Lett. 19239

4. (a) Stiefel E I 1996 Molybdenum Bolsters the Bioinorganic Brigade Science 272 1599; (b) Wuebbens M M and Rajagopalan K V 1995 Investigation of the Early Steps of Molybdopterin Biosynthesis in Escherichia coli through the use of in vivo Labeling Studies J. Biol. Chem. 2701082

5. (a) Westcott B L, Gruhn N E and Enemark J H 1998 Evaluation of Molybdenum-Sulfur Interactions in Molybdoenzyme Model Complexes by Gas-Phase Photoelectron Spectroscopy. The "Electronic Buffer" Effect J. Am. Chem. Soc. 120 3382; (b) McNaughton R, Helton M E, Rubie N D and Kirk M L 2000 The OxoGate Hypothesis and DMSO Reductase: Implications 
for a Psuedo- $\sigma$ Bonding Interaction Involved in Enzymatic Electron Transfer Inorg. Chem. 39 4386; (c) Sarkar S and Das S K 1992 Synthesis of the active sites of molybdoenzymes: $\mathrm{MoO}_{2}$ (VI) and $\mathrm{MoO}$ (IV)dithiolene complexes mimicking enzymatic reactions of sulphite oxidase with saturation kinetics Proc. Indian Acad. Sci. (Chem. Sci.) 104437

6. (a) Malfant L, Cordente N, Lacroix P G and Lepetit C 1998 New Hybrid Materials Combining Nickel Bis (dithiolene) Metal Complexes and Reducible Stilbazolium Cations. A Search for Possible Interplay between Optical Nonlinearity and Conductivity Chem. Mater. 10 4079; (b) Kambe T, Sakamoto R, Kusamoto T, Pal T, Fukui N, Hoshiko K, Shimojima T, Wang Z, Hirahara T, Ishizaka K, Hasegawa S, Liu F and Nishihara H 2014 Redox Control and High Conductivity of Nickel Bis(dithiolene) Complex $\pi$-Nanosheet: A Potential Organic Two-Dimensional Topological Insulator J. Am. Chem. Soc. 136 14357; (c) Kambe T, Sakamoto R, Hoshiko K, Takada K, Miyachi M, Ryu I-H, Sasaki S, Kim J, Nakazato K, Takata M and Nishihara H $2013 \pi$-Conjugated Nickel Bis(dithiolene) Complex Nanosheet J. Am. Chem. Soc. 135 2462; (d) Basu P, Nigam A, Mogesa B, Denti S and Nemykin V 2010 Synthesis, characterization, spectroscopy, electronic and redox properties of a new nickel dithiolene system Inorg. Chim. Acta 3632857

7. Clough A J, Skelton J M, Downes C A, de la Rosa A A, Yoo J W, Walsh A, Melot B C and Marinescu S C 2017 Metallic Conductivity in a Two-Dimensional Cobalt Dithiolene Metal-Organic Framework J. Am. Chem. Soc. 13910863
8. (a) McNamara J P, Hillier I H, Bhachu T S and Garner C D 2005 The nature and function of the catalytic centres of the DMSO reductases Dalton Trans. 21 3572; (b) McNamara W R, Han Z, Alperin P J, Brennessel W W, Holland P L and Eisenberg R 2011 A Cobalt-Dithiolene Complex for the Photocatalytic and Electrocatalytic Reduction of Protons J. Am. Chem. Soc. 13315368

9. Espa D, Pilia L, Marchiò L, Mercuri M L, Serpe A, Barsella A, Fort A, Dalgleish S J, Robertson N and Deplano P 2011 Redox-Switchable Chromophores Based on Metal (Ni, Pd, Pt) Mixed-Ligand Dithiolene Complexes Showing Molecular Second-Order Nonlinear-Optical Activity Inorg. Chem. 502058

10. (a) Madhu V and Das S K 2008 New Series of Asymmetrically Substituted Bis(1,2-dithiolato)-Nickel(III) Complexes Exhibiting Near IR Absorption and Structural Diversity Inorg. Chem. 47 5055; (b) Mueller-Westerhoff U T, Vance B and Yoon D L 1991 The synthesis of dithiolene dyes with strong nearIR absorption Tetrahedron 47909

11. Garreau-de Bonneval B, Ching K I M-C, Alary F, Bui T-T and Valade L 2010 Neutral d8 metal bis-dithiolene complexes: Synthesis, electronic properties and applications Coord. Chem. Rev. 2541457

12. Miao Q, Gao J, Wang Z, Yu H, Luo Y and Ma T 2011 Synthesis and characterization of several nickel bis(dithiolene) complexes with strong and broad nearIR absorption Inorg. Chim. Acta 376619

13. Anderson B M and Hurst S K 2009 Platinum Stacking Interactions in Homoleptic Platinum Polymers Eur. J. Inorg. Chem. 3041 